IJMMS 28:1 (2001) 51-55

PII. S0161171201006202

http://ijmms.hindawi.com

(c) Hindawi Publishing Corp.

\title{
ON THE STRONGLY STARLIKENESS OF MULTIVALENTLY CONVEX FUNCTIONS OF ORDER $\alpha$
}

\author{
MAMORU NUNOKAWA, SHIGEYOSHI OWA, and AKIRA IKEDA
}

(Received 16 November 2000)

\begin{abstract}
The object of the present paper is to derive some sufficient conditions for strongly starlikeness of multivalently convex functions of order $\alpha$ in the open unit disc.

2000 Mathematics Subject Classification. 30C45.
\end{abstract}

1. Introduction. Let $\mathscr{A}(p)$ denote the class of the functions $f(z)=z^{p}+\sum_{n=p+1}^{\infty} a_{n} z^{n}$ which are analytic in the open unit disc $\mathscr{E}=\{z:|z|<1\}$. A function $f(z) \in \mathscr{A}(p)$ is called $p$-valently starlike if and only if the inequality

$$
\operatorname{Re}\left\{\frac{z f^{\prime}(z)}{f(z)}\right\}>0
$$

holds for $z \in \mathscr{E}$. A function $f(z) \in \mathscr{A}(p)$ is called $p$-valently convex of order $\alpha(0 \leq$ $\alpha<p$ ) if and only if the inequality

$$
1+\operatorname{Re}\left\{\frac{z f^{\prime \prime}(z)}{f^{\prime}(z)}\right\}>\alpha
$$

holds for $z \in \mathscr{E}$. We denote by $\mathscr{C}(p, \alpha)$ the family of such functions. A function $f(z) \in$ $\mathscr{A}(p)$ is said to be strongly starlike of order $\alpha(0<\alpha \leq 1)$ if and only if the inequality

$$
\left|\arg \left\{\frac{z f^{\prime}(z)}{f(z)}\right\}\right|<\frac{\pi}{2} \alpha
$$

holds for $z \in \mathscr{E}$. We also denote by $\operatorname{STS}(p, \alpha)$ the family of functions which satisfy the above inequality for the argument. From the definition, it follows that if $f(z) \in$ STS $(p, \alpha)$, then we have

$$
\operatorname{Re}\left\{\frac{z f^{\prime}(z)}{f(z)}\right\}>0 \text { in } \mathscr{E}
$$

or $f(z)$ is $p$-valently starlike in $\mathscr{E}$ and therefore $f(z)$ is $p$-valent in $\mathscr{E}$ (see [1, Lemma 7]).

Nunokawa [2, 3] proved the following theorems.

THEOREM 1.1 (see [2]). If $f(z) \in \mathscr{A}(p)$ satisfies

$$
1+\operatorname{Re}\left\{\frac{z f^{\prime \prime}(z)}{f^{\prime}(z)}\right\}<p+\frac{\alpha}{2},
$$

where $0<\alpha \leq 1$, then $f(z) \in \operatorname{STS}(p, \alpha)$. 
THEOREM 1.2 (see [3]). If $f(z) \in \mathscr{A}(1)$ satisfies

$$
\left|\arg \left\{1+\frac{z f^{\prime \prime}(z)}{f^{\prime}(z)}\right\}\right|<\frac{\pi}{2} \alpha(\beta) \text { in } \mathscr{E},
$$

then

$$
\left|\arg \left\{\frac{z f^{\prime}(z)}{f(z)}\right\}\right|<\frac{\pi}{2} \beta \text { in } \mathscr{E}
$$

where

$$
\begin{aligned}
& \alpha(\beta)=\beta+\frac{2}{\pi} \tan ^{-1}\left\{\frac{\beta q(\beta) \sin (\pi / 2)(1-\beta)}{p(\beta)+\beta q(\beta) \cos (\pi / 2)(1-\beta)}\right\}, \\
& p(\beta)=(1+\beta)^{(1+\beta) / 2}, \quad q(\beta)=(1-\beta)^{(\beta-1) / 2} .
\end{aligned}
$$

It is the purpose of the present paper to prove that if $f(z) \in \mathscr{C}(1,1-(\alpha / 2))$, then $f(z) \in \operatorname{STS}(1, \alpha)$.

In this paper, we need the following lemma.

LEMMA 1.3. Let $f(z) \in \mathscr{A}(1)$ be starlike with respect to the origin in $\mathscr{E}$. Let $C(r, \theta)=$ $\left\{f\left(t e^{i \theta}\right): 0 \leq t \leq r<1\right\}$ and $T(r, \theta)$ be the total variation of $\arg f\left(t e^{i \theta}\right)$ on $C(r, \theta)$, so that

$$
T(r, \theta)=\int_{0}^{r}\left|\frac{\partial}{\partial t} \arg \left\{f\left(t e^{i \theta}\right)\right\}\right| d t
$$

Then

$$
T(r, \theta)<\pi
$$

We owe this lemma to Sheil-Small [6, Theorem 1].

2. Main theorem. Our main theorem for the starlikeness of multivalently convex functions of order $\alpha$ is the following.

THEOREM 2.1. Let $f(z) \in \mathscr{A}(1)$ and

$$
1+\operatorname{Re}\left\{\frac{z f^{\prime \prime}(z)}{f^{\prime}(z)}\right\}>1-\frac{\alpha}{2} \quad \text { in } \mathscr{E},
$$

where $0<\alpha \leq 1$. Then

$$
\left|\arg \left\{\frac{z f^{\prime}(z)}{f(z)}\right\}\right|<\frac{\pi}{2} \alpha \text { in } \mathscr{E},
$$

or $f(z)$ is strongly starlike of order $\alpha$ in $\mathscr{E}$.

Proof. We put

$$
\frac{2}{\alpha}\left\{1+\frac{z f^{\prime \prime}(z)}{f^{\prime}(z)}-1+\frac{\alpha}{2}\right\}=\frac{z g^{\prime}(z)}{g(z)},
$$


where $g(z)=z+\sum_{n=2}^{\infty} b_{n} z^{n}$. From assumption (2.1), we have

$$
\operatorname{Re}\left\{\frac{z g^{\prime}(z)}{g(z)}\right\}>0 \text { in } \mathscr{E} .
$$

This shows that $g(z)$ is starlike and univalent in $\mathscr{E}$. With an easy calculation (cf. [4]), (2.3) gives us that

$$
f^{\prime}(z)=\left\{\frac{g(z)}{z}\right\}^{\alpha / 2}
$$

Since

$$
f^{\prime}(z) \neq 0, \quad 0<|z|<1
$$

we easily have

$$
\frac{f(z)}{z f^{\prime}(z)}=\int_{0}^{1} \frac{f^{\prime}(t z)}{f^{\prime}(z)} d t=\int_{0}^{1} t^{-\alpha / 2}\left\{\frac{g\left(t r e^{i \theta}\right)}{g\left(r e^{i \theta}\right)}\right\}^{\alpha / 2} d t
$$

where $z=r e^{i \theta}$ and $0<r<1$. Since $g(z)$ is starlike in $\mathscr{E}$, from Lemma 1.3, we have

$$
-\pi<\arg \left\{g\left(\operatorname{tr} e^{i \theta}\right)\right\}-\arg \left\{g\left(r e^{i \theta}\right)\right\}<\pi
$$

for $0<t \leq 1$. Putting

$$
\xi=\left\{\frac{g\left(t r e^{i \theta}\right)}{g\left(r e^{i \theta}\right)}\right\}^{\alpha / 2}
$$

we have

$$
\arg s=\frac{\alpha}{2} \arg \left\{\frac{g\left(t r e^{i \theta}\right)}{g\left(r e^{i \theta}\right)}\right\} .
$$

From (2.8) and (2.10), $s$ lies in the convex sector

$$
\left\{s:|\arg s| \leq \frac{\pi}{2} \alpha\right\}
$$

and the same is true of its integral mean of (2.7), (cf. [5, Lemma 1]). Therefore, we have

$$
\left|\arg \left\{\frac{f(z)}{z f^{\prime}(z)}\right\}\right|<\frac{\pi}{2} \alpha \text { in } \mathscr{E}
$$

or

$$
\left|\arg \left\{\frac{z f^{\prime}(z)}{f(z)}\right\}\right|<\frac{\pi}{2} \alpha \text { in } \mathscr{E} .
$$

This shows that

$$
\operatorname{Re}\left\{\frac{z f^{\prime}(z)}{f(z)}\right\}>0 \text { in } \mathscr{E},
$$

which completes the proof of our main theorem. 
REMARK 2.2. This result is sharp for the case $\alpha \rightarrow 0$ and $\alpha=1$.

(a) For the case $\alpha \rightarrow 0$, put $f(z)=z$, then $f(z)$ is a convex function of order $1-$ $(\alpha / 2) \rightarrow 1$ and $f(z)$ then $f(z)$ is a strongly starlike function of order $\alpha \rightarrow 0$.

(b) For the case $\alpha=1$, put

$$
1+\frac{z f^{\prime \prime}(z)}{f^{\prime}(z)}=\frac{1}{1-z}
$$

Then we have

$$
1+\operatorname{Re}\left\{\frac{z f^{\prime \prime}(z)}{f^{\prime}(z)}\right\}>\frac{1}{2} \quad \text { in } \mathscr{E}
$$

and therefore $f(z)$ is a convex function of order $1 / 2$. From (2.10), we easily have

$$
f^{\prime}(z)=\frac{1}{1-z}, \quad f(z)=\log \left\{\frac{1}{1-z}\right\} .
$$

Putting $|z|=1, z=e^{i \theta}, 0 \leq \theta<2 \pi$, then it follows that

$$
\begin{aligned}
\frac{z}{1-z} & =-\frac{1}{2}+i \frac{\cos (\theta / 2)}{2 \sin (\theta / 2)}, \\
\log \left\{\frac{1}{1-z}\right\}= & \log \left|\frac{1}{2}+i \frac{\cos (\theta / 2)}{2 \sin (\theta / 2)}\right|+i \arg \left\{\frac{1}{2}+i \frac{\cos (\theta / 2)}{2 \sin (\theta / 2)}\right\} . \\
\lim _{\theta \rightarrow+0} \arg \left\{\frac{z f^{\prime}(z)}{f(z)}\right\}= & \lim _{\theta \rightarrow+0} \arg \left\{\frac{z /(1-z)}{\log (1 /(1-z))}\right\} \\
= & \lim _{\theta \rightarrow+0} \arg \left\{-\frac{1}{2}+i \frac{\cos (\theta / 2)}{2 \sin (\theta / 2)}\right\} \\
& -\lim _{\theta \rightarrow+0} \arg \left\{\log \left|\frac{1}{2}+i \frac{\cos (\theta / 2)}{2 \sin (\theta / 2)}\right|+i \arg \left(\frac{1}{2}+i \frac{\cos (\theta / 2)}{2 \sin (\theta / 2)}\right)\right\} \\
= & \frac{\pi}{2} .
\end{aligned}
$$

The above shows that the main theorem is sharp for the case $\alpha \rightarrow 0$ and $\alpha=1$.

Applying the same method as above and [2], we can obtain the following result.

THEOREM 2.3. If $f(z) \in A(p)$ and satisfies

$$
p-\frac{\alpha}{2}<1+\operatorname{Re}\left\{\frac{z f^{\prime \prime}(z)}{f^{\prime}(z)}\right\} \quad \text { in } \mathscr{E},
$$

where $0<\alpha \leq 1$, then $f(z) \in \operatorname{STS}(p, \alpha)$.

\section{REFERENCES}

[1] M. Nunokawa, On the theory of multivalent functions, Tsukuba J. Math. 11 (1987), no. 2, 273-286. MR 89d:30013. Zbl 639.30014.

[2] _ _ On certain multivalently starlike functions, Tsukuba J. Math. 14 (1990), no. 2, 275277. MR 92b:30016. Zbl 728.30014.

[3] _ On the order of strongly starlikeness of strongly convex functions, Proc. Japan Acad. Ser. A Math. Sci. 69 (1993), no. 7, 234-237. MR 95f:30019. Zbl 793.30007. 
[4] M. Nunokawa and S. Owa, On certain subclass of analytic functions, Indian J. Pure Appl. Math. 19 (1988), no. 1, 51-54. MR 89c:30029. Zbl 646.30020.

[5] C. Pommerenke, On close-to-convex analytic functions, Trans. Amer. Math. Soc. 114 (1965), 176-186. MR 30\#4920. Zbl 132.30204.

[6] T. Sheil-Small, Some conformal mapping inequalities for starlike and convex functions, J. London Math. Soc. (2) 1 (1969), 577-587. MR 40\#2842. Zbl 201.40803.

MAMORU NunOKawa: Department of Mathematics, University of GunMa, ARAMAKi MAEBASHI GUNMA, 371-8510, JAPAN

E-mail address: nunokawa@edu.gunma-u.ac.jp

Shigeyoshi OWa: Department of Mathematics, Kinki University, Higashi-OSAKa, OSAKA 577-8502, JAPAN

E-mail address: owa@math.kindai .ac.jp

AKIRA IKEDA: DEPARTMENT OF APPLIED MATHEMATICS, FUKUOKA UNIVERSITY, NANAKUMA JONAN-KU FUKUOKA, 814-0180, JAPAN

E-mail address: aikeda@sf.sm. fukuoka-u.ac.jp 


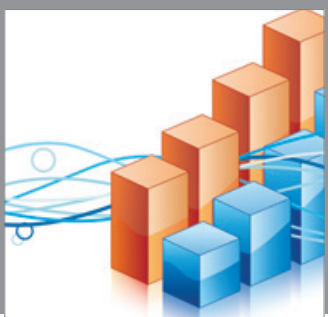

Advances in

Operations Research

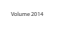

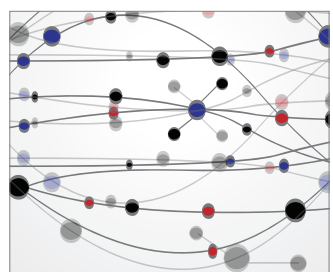

\section{The Scientific} World Journal
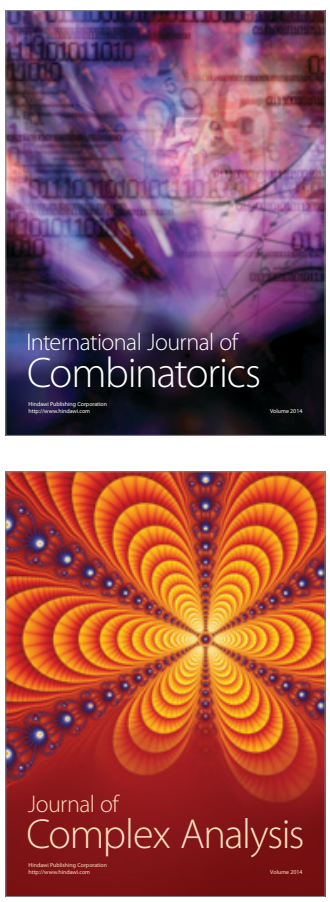

International Journal of

Mathematics and

Mathematical

Sciences
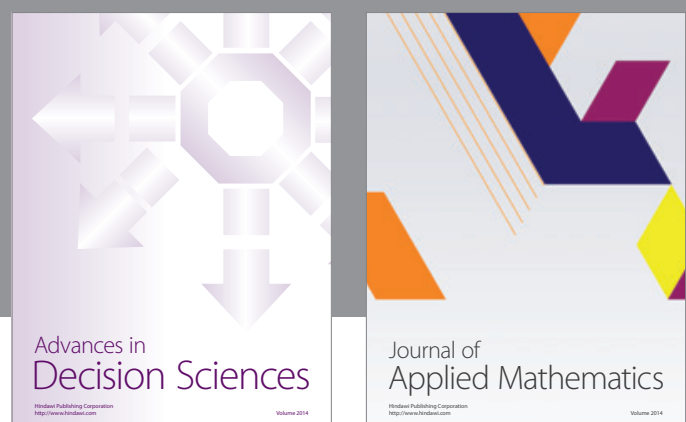

Journal of

Applied Mathematics
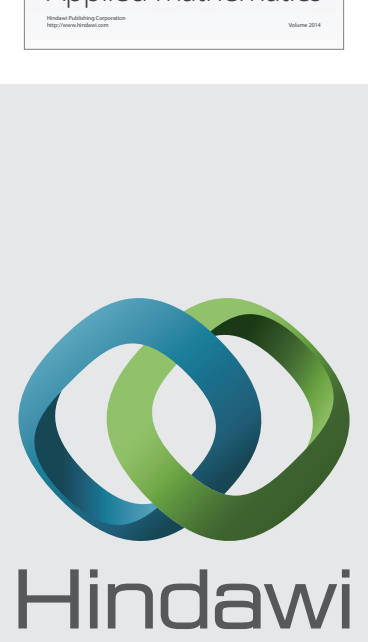

Submit your manuscripts at http://www.hindawi.com
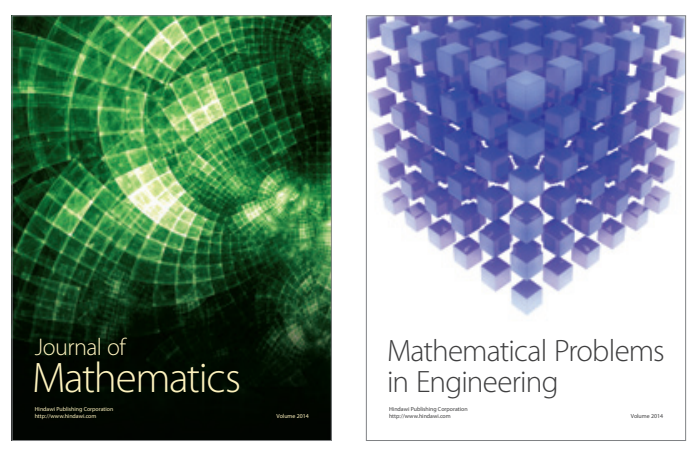

Mathematical Problems in Engineering
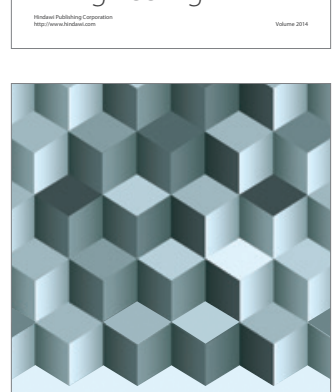

Journal of

Function Spaces
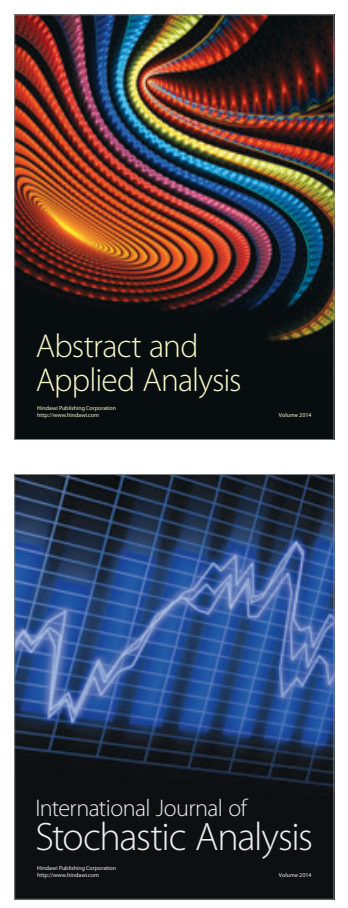

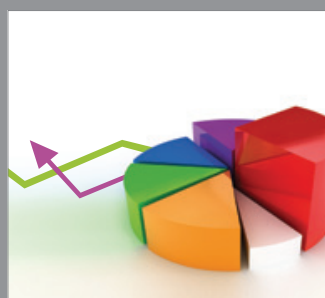

ournal of

Probability and Statistics

Promensencen
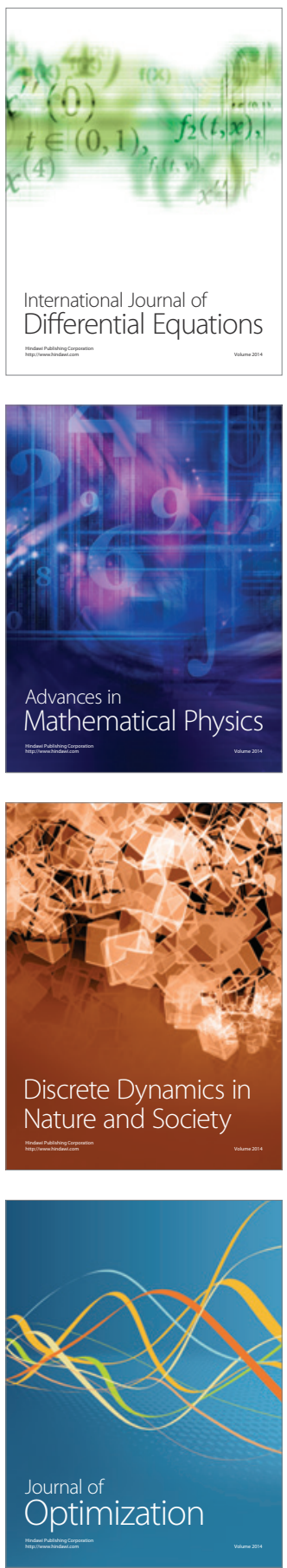